Journal of Applied Pharmaceutical Science Vol. 6 (06), pp. 079-082, June, 2016

Available online at http://www.japsonline.com

DOI: $10.7324 / \mathrm{JAPS} .2016 .60614$

ISSN 2231-3354 (cc) BY-NC-SA

\title{
Triterpenes and sterols from Hoya diversifolia Blume
}

\author{
Nelson M. Panajon ${ }^{1,2}$, Fernando B. Aurigue ${ }^{3}$, Chien-Chang Shen ${ }^{4}$, Consolacion Y. Ragasa ${ }^{1,5^{*}}$ \\ ${ }^{1}$ Chemistry Department, De La Salle University, 2401 Taft Avenue, Manila 1004, Philippines. ${ }^{2}$ Chemistry Department, Central Luzon State University, \\ Munoz, Nueva Ecija 3121, Philippines. ${ }^{3}$ Agriculture Research Section, Atomic Research Division, Philippine Nuclear Research Institute-Department of \\ Science and Technology, Commonwealth Avenue, Diliman, Quezon City 1101, Philippines. ${ }^{4}$ National Research Institute of Chinese Medicine, Ministry of \\ Health and Welfare, 155-1, Li-Nong St., Sec. 2, Taipei 112, Taiwan. ${ }^{5}$ Chemistry Department, De La Salle University Science \& Technology Complex \\ Leandro V. Locsin Campus, Biñan City, Laguna 4024, Philippines.
}

\section{ARTICLE INFO \\ Article history: \\ Received on: 27/02/2016 \\ Revised on: 21/03/2016 \\ Accepted on: 01/05/2016 \\ Available online: 28/06/2016}

\section{Key words:}

Hoya diversifolia Blume, Apocynaceae, $\beta$-amyrin

cinnamate, lupeol cinnamate,

squalene, $\beta$-sitosterol, $\alpha$ -

amyrin, $\beta$-amyrin, lupeol,

taraxerol, stigmasterol.

\begin{abstract}
Chemical investigation of the dichloromethane extracts of Hoya diversifolia Blume led to the isolation of $\beta$ amyrin cinnamate (1), squalene (2), $\beta$-sitosterol (3), a mixture of $\beta$-amyrin (4a), $\alpha$-amyrin (4b) and lupeol (4c) in a 4:2:1 ratio and saturated hydrocarbons from the leaves; and 2, taraxerol (5), lupeol cinnamate (6), and a mixture of 3 and stigmasterol (7) in a 2:1 ratio from the stems. The structures of 1-7 were identified by comparison of their NMR data with those reported in the literature.
\end{abstract}

\section{INTRODUCTION}

Hoya plants are also called wax plants due to the waxy appearance of their leaves or flowers. There are at least 109 species of Hoya found in the Philippines, 88 of these are endemic to the country. Hoya diversifolia Blume is an indigenous Philippine ornamental plant found in Palawan and Luzon, specifically Quezon Province (Aurigue, 2013). It is distributed in Myanmar, Indo-China, peninsular Thailand, Peninsular Malaysia, Singapore, Sumatra and Java (Mansur, 2003). An earlier study reported that $H$. diversifolia afforded apigenin- $O$-glycoside, apigenin-di- $C$-glycoside, vitexin and isovitexin. The extract of this plant exhibited strong antinematodal activity against the pine wood nematode Bursaphelenchus xylophilus. In Malaysia and

\footnotetext{
* Corresponding Author

Email: consolacion.ragasa@dlsu.edu.ph

Tel./Fax: +6325360230
}

Vietnam, a decoction of the leaves of $H$. diversifolia is used as a bath to treat rheumatism (Mansur, 2003). Another study reported that $H$. diversifolia contains $11.1 \%$ free terpenoids and $81.7 \%$ triterpene cinnamates (Warnaar, 1984). This study is part of our research on the chemical constituents of Philippine native hoyas. We earlier reported the isolation of lupenone and lupeol from the roots; lupeol, squalene and $\beta$-sitosterol from the leaves; and betulin from the stems of $H$. mindorensis Schlechter (Ebajo et al., 2014). In another study, we reported the isolation of lupeol, $\alpha$-amyrin, $\beta$ amyrin, lupeol acetate, $\alpha$-amyrin acetate, and $\beta$-amyrin acetate from the stems; and $\alpha$-amyrin, bauerenol, squalene, lutein, $\beta$ sitosterol, and stigmasterol from the leaves of $H$. multiflora Blume (Ebajo et al., 2015a). Recently, the isolation of $\beta$-amyrin cinnamate and taraxerol from the stems; and taraxerol, triglycerides, chlorophyll a, and a mixture of $\beta$-sitosterol and stigmasterol from the leaves of $H$. wayetii Kloppenb has been reported (Ebajo et al., 2015b). 
Furthermore, the isolation of taraxerol, taraxerone, a mixture of $\beta$-sitosterol and stigmasterol in about 2:1 ratio, and a mixture of $\alpha$-amyrin cinnamate and $\beta$-amyrin cinnamate in about $1: 2$ ratio from the stems; taraxerol, taraxerone, and $\beta$-sitosterol from the roots; a mixture of $\alpha$-amyrin cinnamate and $\beta$-amyrin cinnamate in about 3:2 ratio from the flowers; and squalene, $\beta$ sitosterol, and saturated hydrocarbons from the leaves of $\mathrm{H}$. buotii has been reported (Ebajo et al., 2015c). We report herein the isolation of $\beta$-amyrin cinnamate (1), squalene (2), $\beta$-sitosterol (3), and a mixture of $\beta$-amyrin (4a), $\alpha$-amyrin (4b) and lupeol (4c) in a 4:2:1 ratio and saturated hydrocarbons from the leaves; and $\mathbf{2}$, taraxerol (5), lupeol cinnamate (6), and a mixture of $\mathbf{3}$ and stigmasterol (7) in a 2:1 ratio from the stems of $H$. diversifolia. The chemical structures of 1-7 are presented in Fig. 1.
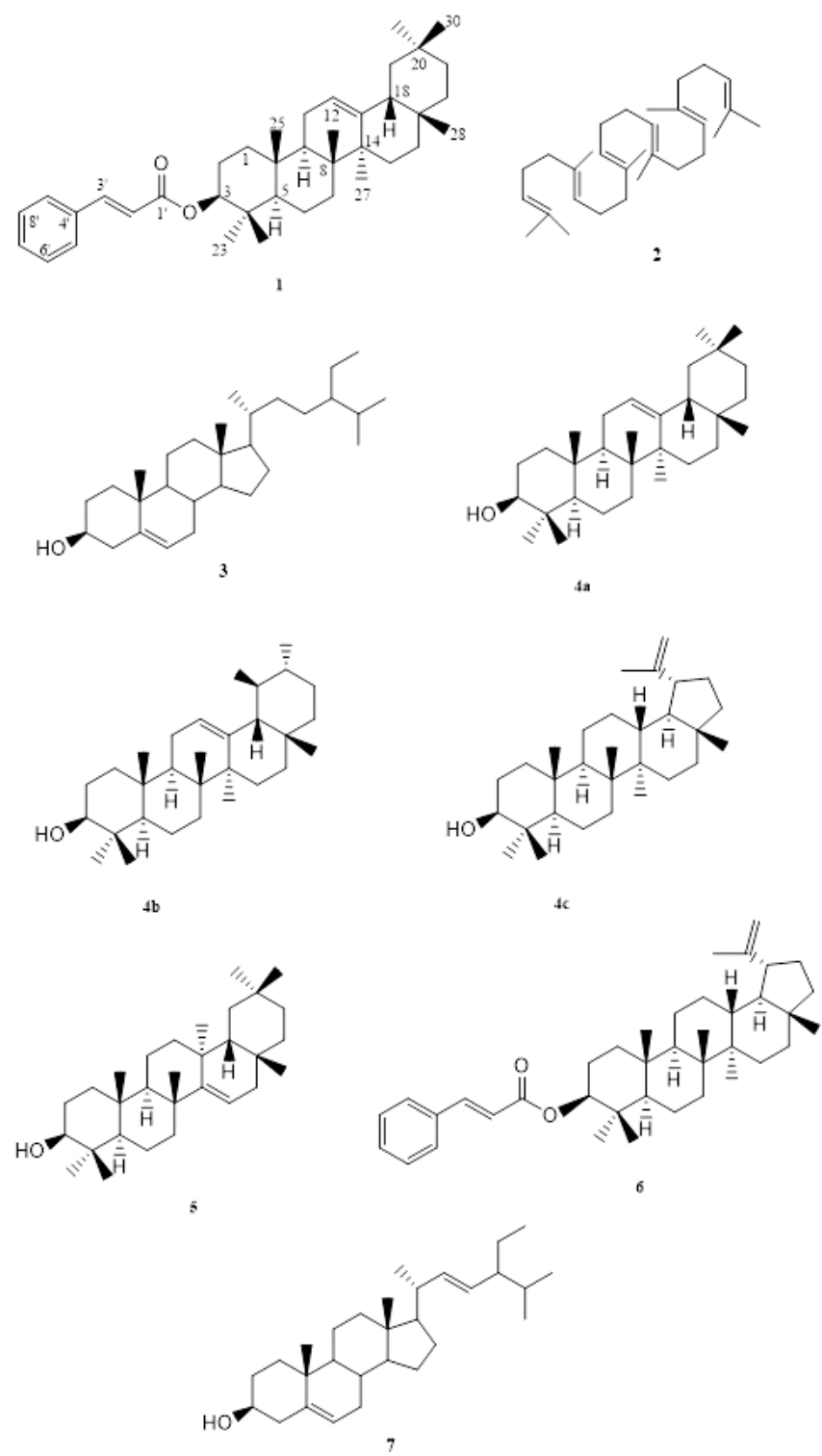

Fig 1. Chemical structures of $\beta$-amyrin cinnamate (1), squalene (2), $\beta$-sitosterol (3), $\beta$-amyrin (4a), $\alpha$-amyrin (4b), lupeol (4c), taraxerol (5), lupeol cinnamate (6), and stigmasterol (7) from Hoya diversifolia.

\section{MATERIALS AND METHODS}

\section{General Experimental Procedure}

NMR spectra were recorded on a Varian VNMRS spectrometer in $\mathrm{CDCl}_{3}$ at $600 \mathrm{MHz}$ for ${ }^{1} \mathrm{H}$ NMR and $150 \mathrm{MHz}$ for ${ }^{13} \mathrm{C}$ NMR spectra. Column chromatography was performed, with silica gel 60 (70-230 mesh). Thin layer chromatography, was performed with plastic backed plates coated with silica gel $\mathrm{F}_{254}$ and the plates were visualized by spraying with vanillin $/ \mathrm{H}_{2} \mathrm{SO}_{4}$ solution followed by warming.

\section{Sample Collection}

Healthy vines of Hoya diversifolia Blume were collected from the Philippine Nuclear Research Institute Hoya Germplasm Collection with Accession Number H.034 under MTA No. 2015002 dated January 20, 2015. The plants were propagated by stem cuttings from an established material originally obtained from Lucban, Quezon Province, Luzon Island, Philippines. The species is authenticated by one of the authors (FBA).

\section{General Isolation Procedure}

The air-dried leaves $(157.2 \mathrm{~g})$, and stems $(383.9 \mathrm{~g})$ of $H$. diversifolia were ground in a blender, soaked in $\mathrm{CH}_{2} \mathrm{Cl}_{2}$ for three days and then filtered. The filtrates were concentrated under vacuum to afford crude extracts of leaves $(9.1 \mathrm{~g})$, and stems (11.75 g) which were each chromatographed by gradient elution with $\mathrm{CH}_{2} \mathrm{Cl}_{2}$, followed by increasing amounts of acetone at $10 \%$ increment by volume as eluents. A glass column 18 inches in height and 1 inch internal diameter was used for the fractionation of the crude extracts. Eleven $20 \mathrm{~mL}$ fractions were collected. A glass column 12 inches in height and 0.5 inch internal diameter was used for the rechromatography of fractions from the crude extracts. $2 \mathrm{~mL}$ fractions were collected. Fractions with spots of the same $R_{f}$ values were combined and rechromatographed in appropriate solvent systems until TLC pure isolates were obtained. Rechromatography and final purifications were conducted using Pasteur pipettes as columns. $1 \mathrm{~mL}$ fractions were collected.

\section{Isolation of Chemical Constituents of the Leaves}

The $10 \%$ acetone in $\mathrm{CH}_{2} \mathrm{Cl}_{2}$ fraction from the chromatography of the crude extract was rechromatographed using $1 \%$ EtOAc in petroleum ether. $1 \mathrm{~mL}$ fractions were collected. Fractions 7-12 yielded 2 (5 mg), while fractions 1-5 afforded saturated hydrocarbons $(6 \mathrm{mg})$. The $20 \%$ acetone in $\mathrm{CH}_{2} \mathrm{Cl}_{2}$ fraction was rechromatographed using $2.5 \%$ EtOAc in petroleum ether and portions of $2 \mathrm{~mL}$ fractions were collected. Fractions $17-$ 21 were combined to yield $\mathbf{1}$ ( $3 \mathrm{mg}$ ) after washing with petroleum ether. The $40 \%$ acetone in $\mathrm{CH}_{2} \mathrm{Cl}_{2}$ fraction was rechromatographed using $10 \%$ EtOAc in petroleum ether, followed by $15 \%$ EtOAc in petroleum ether. $1 \mathrm{~mL}$ fractions were collected. Fractions 5-6 eluted with $10 \%$ EtOAc in petroleum ether afforded a mixture of 
4a, 4b and 4c (4 mg) after washing with petroleum ether. The 1013 fractions eluted with $15 \%$ EtOAc in petroleum ether afforded 3 (5 mg) after washing with petroleum ether.

\section{Isolation of Chemical Constituents of the Stems}

The $10 \%$ acetone in $\mathrm{CH}_{2} \mathrm{Cl}_{2}$ fraction from the chromatography of the crude extract was rechromatographed using petroleum ether and $1 \mathrm{~mL}$ fractions were collected. Fraction 16 afforded $2(5 \mathrm{mg})$. The $20 \%$ acetone in $\mathrm{CH}_{2} \mathrm{Cl}_{2}$ fraction was rechromatographed using $2.5 \%$ EtOAc in petroleum ether and 1$\mathrm{mL}$ fractions were collected. Fractions 11-19 from this column were combined and rechromatographed using $1 \%$ EtOAc in petroleum ether. $1 \mathrm{~mL}$ fractions were collected. The $12^{\text {th }}$ fraction afforded 6 (2 mg) after washing with petroleum ether. The 30\% acetone in $\mathrm{CH}_{2} \mathrm{Cl}_{2}$ fraction was rechromatographed using $15 \%$ EtOAc in petroleum ether and $1 \mathrm{~mL}$ fractions were collected. Fractions 15-20 were combined and rechromatographed using $\mathrm{CH}_{3} \mathrm{CN}: \mathrm{Et}_{2} \mathrm{O}: \mathrm{CH}_{2} \mathrm{Cl}_{2}$ (0.5:0.5:9, v/v) and $1 \mathrm{~mL}$ fractions were collected. Fractions 10-12 yielded 5 (3 mg) after washing with petroleum ether. The $40 \%$ acetone in $\mathrm{CH}_{2} \mathrm{Cl}_{2}$ fraction was rechromatographed using $\mathrm{CH}_{3} \mathrm{CN}: \mathrm{Et}_{2} \mathrm{O}: \mathrm{CH}_{2} \mathrm{Cl}_{2}$ (0.5:0.5:9, v/v) and $1 \mathrm{~mL}$ fractions were collected. Fractions 5-10 were combined and rechromatographed using $\mathrm{CH}_{3} \mathrm{CN}: \mathrm{Et}_{2} \mathrm{O}: \mathrm{CH}_{2} \mathrm{Cl}_{2}$ (0.5:0.5:9, $\mathrm{v} / \mathrm{v}$ ) and $1 \mathrm{~mL}$ fractions were collected. Fractions 3-5 were combined to yield a mixture of $\mathbf{3}$ and $\mathbf{7}(2 \mathrm{mg})$ after washing with petroleum ether.

\section{RESULTS AND DISCUSSION}

Silica gel chromatography of the dichloromethane extracts of $H$. diversifolia yielded 1-7 and saturated hydrocarbons. The NMR spectra of $\mathbf{1}$ are in accordance with data reported in the literature for $\beta$-amyrin cinnamate (Akihisa et al., 2010; Ebajo et al., 2015c); 2 for squalene (Ragasa et al., 2014b; 2014c); 3 for $\beta$ sitosterol (Ragasa et al., 2013b); 4a for $\beta$-amyrin (Ragasa et al., 2013b); 4b for $\alpha$-amyrin (Ragasa et al., 2013b); 4c for lupeol (Ragasa et al., 2013b); 5 for taraxerol (Tareq et al., 2009; Ragasa et al., 2014a; Ebajo et al., 2015b, 2015c); 6 for lupeol cinnamate (Akihisa et al., 2010; Lakshmi et al., 2014); 7 for stigmasterol (Ragasa et al., 2013b); and saturated hydrocarbons (Ebajo et al., 2015c).

The 4:2:1 ratio of the mixture of $\beta$-amyrin (4a), $\alpha$-amyrin (4b) and lupeol (4c) was deduced from the intensities and integrations of the ${ }^{1} \mathrm{H}$ NMR resonances for the olefinic protons of 4a at $\delta 5.16(\mathrm{t}, J=3.6 \mathrm{~Hz})$ (Ragasa et al., 2013b), 4b at $\delta 5.11(\mathrm{t}, J$ $=3.6 \mathrm{~Hz})$ (Ragasa et al., 2013b), and $4 \mathrm{c}$ at $\delta 4.67(\mathrm{~d}, J=2.4 \mathrm{~Hz})$ and 4.55. (d, $J=2.4 \mathrm{~Hz}$ ) (Ragasa et al., 2013b). The 2:1 ratio of $\beta$-sitosterol (3) and stigmasterol (7) was deduced from the intensities and integrations of the ${ }^{1} \mathrm{H}$ NMR resonances for olefinic protons at $\delta 5.35(\mathrm{~d}, J=4.8 \mathrm{~Hz}, \mathrm{H}-5)$ and methyl protons at $\delta 0.66$ (s) for 3 and olefinic protons at $\delta 5.35(\mathrm{~d}, J=4.8 \mathrm{~Hz}, \mathrm{H}-5), 5.13$ $(\mathrm{dd}, \mathrm{J}=8.4,15.6 \mathrm{~Hz})$ and $5.00(\mathrm{dd}, \mathrm{J}=8.4,15.0 \mathrm{~Hz})$ and the methyl protons at $\delta 0.68$ (s) for 7 (Ragasa et al., 2013b). These results indicate that $H$. diversifolia shares similar chemical characteristics with other members of the genus Hoya: H. wayetii (Ebajo et al., 2015b) and H. buotii (Ebajo et al., 2015c) which yielded $\beta$-amyrin cinnamate (1) and taraxerol (5); H. mindorensis (Ebajo et al., 2014), H. multiflora (Ebajo et al., 2015a), H. wayetii (Ebajo et al., 2015b) and H. buotii (Ebajo et al., 2015c) which contained $\beta$-sitosterol (3) and stigmasterol (7); H. mindorensis (Ebajo et al., 2014), H. multiflora (Ebajo et al., 2015a) and $H$. buotii (Ebajo et al., 2015c) which afforded squalene (2); and $H$. multiflora (Ebajo et al., 2015a) which yielded $\beta$-amyrin (4a) and $\alpha$-amyrin (4b).

\section{CONCLUSION}

Hoya diversifolia Blume is an ornamental plant native to the Philippines and other Asian countries with chemical constituents from dichloromethane extracts identified as follows: $\beta$-amyrin cinnamate, squalene, $\beta$-sitosterol, a mixture of $\beta$-amyrin, $\alpha$-amyrin and lupeol in a 4:2:1 ratio, and saturated hydrocarbons from the leaves; and taraxerol, lupeol cinnamate, and a mixture of $\beta$-sitosterol and stigmasterol in a 2:1 ratio from the stems.

\section{ACKNOWLEGEMENT}

A research grant from the De La Salle University Science Foundation through the University Research Coordination Office is gratefully acknowledged.

\section{REFERENCES}

Akihisa T, Kojima N, Kikuchi T, Yasukawa K, Tokuda H, Masters ET, Manosroi A, Manosroi J. Anti-inflammatory and chemopreventive effects of triterpene cinnamates and acetates from shea fat. J Oleo Sci, 2010; 59(6):273-280.

Aurigue FB. 2013. A Collection of Philippine Hoyas and Their Culture, Philippine Council for Agriculture, Aquatic and Natural Resources Research and Development (PCAARRD). Department of Science and Technology (DOST). 195 pages.

Ebajo Jr VD, C-C Shen, Ragasa CY. Triterpenes and sterol from Hoya mindorensis. Der Pharma Chemica, 2014; 6(4):321-325.

Ebajo Jr VD, Shen C-C, Ragasa CY. Terpenoids and sterols from Hoya multiflora Blume. J Appl Pharm Sci, 2015a; 5(3):33-39.

Ebajo Jr VD, Aurigue FB, Brkljača R, Urban S, Ragasa CY. Chemical constituents of Hoya wayetii Kloppenb. Int J Pharmacog Phytochem Res, 2015b; 7(5):1041-1045.

Ebajo Jr VD, Brkljača R, Urban S, Ragasa CY. Chemical constituents of Hoya buotii Kloppenb. J Appl Pharm Sci, 2015c; 5(11):6972 .

Lakshmi V, Mahdi AA, Ahmad MK, Agarwal SK, Srivastava AK. Antidiabetic activity of lupeol and lupeol esters in streptozotocin induced diabetic rats. Bangladesh Pharm J, 2014; 17(2):138-146.

Mansur M, Hoya R.Br. In: Lemmens RHMJ, Bunyapraphatsara N (eds.): Plant Resources of South-East Asia No. 12(3), Medicinal and Poisonous Plants 3. Prosea Foundation, Bogor, Indonesia. 2003; pp. 244247.

Ragasa CY, Cornelio K. Triterpenes from Euphorbia hirta and their cytotoxicity. Chin J Nat Med, 2013a; 11(5):528-533.

Ragasa CY, Torres OB, Tongco JVV, Razal RA, Shen C-C. Chemical constituents of Petersianthus quadrialatus Merr. Res J Pharm Biol Chem Sci, 2014a; 5(4):181-186.

Ragasa CY, Lorena GS, Mandia EH, Raga DD, Shen C-C. Chemical constituents of Abrus precatorius. Amer J Essent Oils Nat Prod, 2013b; 1(2):7-10. 
Ragasa CY, Ng VAS, De Los Reyes MM, Mandia EH, Oyong GG, Shen C-C. Chemical constituents and cytotoxicity of the leaves of Dysoxylum gaudichaudianum (A. Juss.) Miq. Der Pharma Chemica, 2014b; 6(5):182-187.

Ragasa CY, Ng VAS, Ebajo Jr V, De Los Reyes MM, Mandia EH, Shen C-C, Chemical Constituents of Pipturus arborescens. Der Pharmacia Lettre. 2014c; 6(6):35-42.

Tareq FS, Sohrab MdH, Chowhdury AMSU, Afroz F, AlMansur M, Hasan CM. Phytochemical studies on the leaves of Xylia dolabriformis. Dhaka Univ J Pharm Sci, 2009; 8(2):171-172.
Warnaar F. Aromatic and fatty acids of triterpene esters and rubber content of Hoya latices and their taxonomic significance. Phytochem, 1984; 23 (5):1049-1053.

\section{How to cite this article:}

Panajon NM, Aurigue FB, Shen CC, Ragasa CY. Triterpenes and sterols from Hoya diversifolia Blume. J App Pharm Sci, 2016; 6 (06): 079-082. 